\title{
Using a Public Safety Radio Network for Information Negotiation between the Three-Tiered Command and Control Structure
}

\author{
Kristine Steen-Tveit \\ Centre for Integrated Emergency Management \\ Dept. of Information Systems, \\ University of Agder, Norway \\ kristine.steen-tveit@uia.no
}

\begin{abstract}
Multi-organizational emergency operations require effective information sharing. Existing information management tools supporting a common operational picture mainly convey factual information. However, a growing body of literature recognizes the importance of sharing interpretations and implications among the involved stakeholders for building a common situational understanding. This study aims to identify information that must be negotiated across the strategic, tactical, and operational command and control structures (C2S) for developing common situational understanding. Based on 33 interviews and a survey of emergency management stakeholders, information elements on the semantic and pragmatic levels are identified. Further, the results suggest how to use a secure radio network for facilitating information sharing so that the involved organizations can monitor and negotiate important information. These insights provide important lessons for improving information sharing in the emergency management domain.
\end{abstract}

\section{Introduction}

The importance of a common situational understanding for successful multi-organizational emergency management is well acknowledged in both research and practice [1], and the involved organizations require technical and organizational interoperability with common structures and processes for successful interaction [2]. In reality, the involved organizations have different communication structures, heterogeneous information needs, [3,4,5], different mandates and objectives [6], and many technologies with no interoperability [7]. These combined factors make the process of sharing information very demanding for the involved stakeholders. Radio networks are a commonly used technology for interactive verbal communication between different stakeholders in crisis operations.
However, there is a need for more knowledge on how this can be exploited in the best possible way.

The common operational picture (COP) is a collective term for many suggested technical solutions for data collection and distribution [8]. For example, using text in logging systems or e-mail with or without various attachments are elements in COPs. Actors collect information that fits their professional standpoint and therefore develop different perspectives of the situation. Following this, the sensemaking process is an important component when focusing on information sharing to achieve common situational understanding [4].

Most of the information presented in the COP is factual and not sufficient for decision-makers to build a common situational understanding in complex emergency operations [9]. In fact, there is a need for information sharing at the syntactic level of factual information, the semantic level of interpretations, and the pragmatic level of implications to interpret the facts [10]. However, thus far, little attention has been paid to the role of the more implicit and complex concerns at the semantic and pragmatic level in the information sharing doctrine related to multiorganizational emergency management [9]. Therefore, this study examines the following research question: What information elements must be exchanged at the semantic and pragmatic levels between the involved organizations in large complex events, and how can this be facilitated by using a radio network?

To answer this question, literature on multiorganizational emergency management, multiteam technologies for supporting COP, and common situational understanding were reviewed. The empirical basis for this study was comprised of interviews with 33 emergency stakeholders from different emergency management organizations in Norway. A survey conducted after a multiorganizational exercise was also included. The data collection focused on large forest fires and extreme weather events, as these scenarios are expected to increase in frequency and scope due to climate 
changes and requiring multi-organizational emergency management at several levels.

The analysis suggests that while factual information can benefit from being displayed in a $\mathrm{COP}$, there are specific information elements at the semantic and pragmatic levels, such as information related to the security and severity of the incident, that must be verbally negotiated for developing common situational understanding. This insight provides important lessons on how to connect the three-tiered C2S with up-to-date semantic and pragmatic information by the pre-definition of information elements, information managers, and communication paths, using a secure radio network.

Further, the results contribute to the expanding field of the information sharing doctrine [9] by identifying the more implicit, and complex concerns at the semantic and pragmatic level related to multiorganizational emergency management.

The study offers general lessons on the universal principles of the strategic, tactical and, operational command and control structure in emergency management. Furthermore, focusing on multiorganizational collaborative communication using a secure radio network during emergency management can provide valuable support during the COVID-19 pandemic.

\section{Multi-organizational emergency management}

In large, complex events, emergency response requires the involvement of several governmental, non-governmental, and volunteer organizations [12]. This is a cooperative process where the involved actors must be active and coordinated in a mutual dependency, and flaws in this collaboration have been shown in many real-world cases to result in inefficient outcomes [13]. Several factors need to be addressed for effective collaboration: technologies for supporting the COP, knowledge of each other's responsibilities and tasks, and establishment of common situational understanding [14]. However, without key information concerning the emergency event, cooperation is not a sufficient solution [15]. With more supporting organizations to be connected, the complexity of the communication increases. Undoubtedly, this is affected by information needs and prioritization challenges, and accordingly makes information sharing in such complex networks a problematic task.

The front line includes the first responders that address the situation based on their professional expertise, known as the "knowledge by acquaintance." The supportive organizations at the tactical and strategic command and control structure are the administrative executives who formally provide direction and make decisions with potential long-term consequences, known as the "knowledge by description" [16]. Insufficient key information results in situational uncertainty and henceforward decisionmaking errors with possibly destructive consequences [8] such as escalation of quickly developing incidents.

Universally, emergency management is divided into four phases: mitigation, preparedness, response, and recovery [17]. Extreme weather events tend to hit society with cascading effects by threatening human lives and damaging critical infrastructure. The first hours of such events are colored by chaos and complexity, and an effective operation in this critical timeline is crucial for outcome success. Therefore, the focus in this article is on the response phase.

In Norway, like many other countries, the emergency response system consists of several teams from different organizations (e.g. first-responders including operative units and emergency dispatchers in the command and control centers (C3), municipalities, civil defense, red cross, and the county governor) operating as a three-tiered hierarchical command and control structure (C2S) [18]. This structure illustrates the management levels (Figure 1). For example, the operational $\mathrm{C} 2 \mathrm{~S}$ is defined as the first responders working on the scene, the tactical $\mathrm{C} 2 \mathrm{~S}$ is the local incident management teams supporting the actors on the scene, and the strategic C2S is the stakeholders working at the regional, state, or national level [19,20]. Literature refers to the different levels as the front line (operational level) and the remote response network (tactical/strategic C2S) [9].

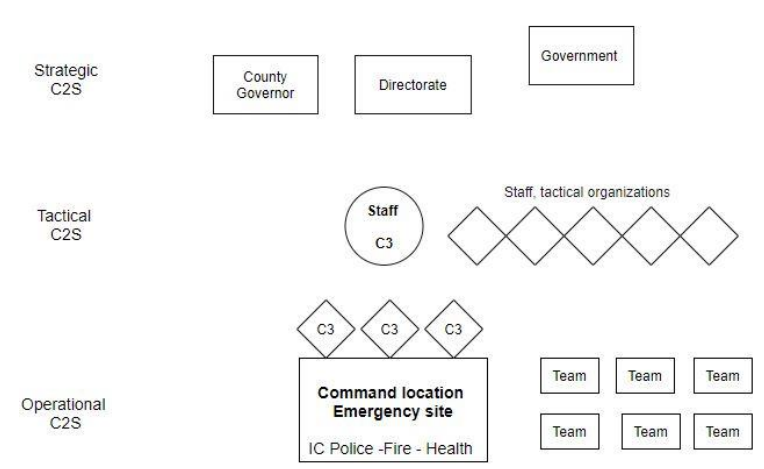

Figure 1: The three-tiered command and control structure (C2S)

\subsection{Technologies for supporting the COP}

Without technologies as a platform for collecting and sharing information during emergency operations, the emergency management process as we know it today would be impossible. However, the effectiveness of the technology is still determined by 
several factors such as system flexibility, interoperability across the involved organizations, knowledge on how to use the systems, and infrastructure vulnerability [18].

Although there is no univocal definition of a COP $[22,4$,$] , it is largely framed as a technical system that$ aims to support the processes of decision-making [5] and collaboration between the different command and control structures [22]. It is illustrated in the literature as an efficient solution for information sharing and hence supports the stakeholders in building an adequate situational awareness (SA) [23] during emergency operations [5]. The COP also prevents a lack of information by making operational information accessible to the involved stakeholders. Therefore, the COP can be seen as an "information warehouse" [24] where the information is stored and available for stakeholders to collect organization-specific information. The COP originated from the military context as a "centralized information display system" [25] and has further been defined as a single identical display of relevant operational information shared by emergency management practitioners [6]. This information can be transferred between the involved organizations through the COP as long as the syntactic differences and dependencies between the stakeholders are known. As the emergency event evolves, the differences and dependencies become blurred resulting in different semantic interpretations and the need for pragmatic negotiation.

2.1.1 Public safety radio network. Handheld radio networks are frequently used for interactive communication between different stakeholders in crisis operations. Stakeholders use different channels depending on their roles and information needs [18]. The Norwegian Public Safety Network (NPSN) was implemented in 2015 and replaced all other verbal communication systems in the first responder agencies. Other organizations beyond the first responders have since been connected to the NPSN, including non-governmental organizations, many municipalities, county governors, private critical infrastructure organizations, and several other public resources. As of May 2021, there are 59,517 subscribers to the NPSN [26]. The terminals are GPS traced. One of the most important functions in the NPSN for multi-organizational communication is the ability to set up different call groups or "digital rooms." It is possible to set up several call groups, both agency-specific and cross-organizational, during one emergency operation [27]. Although user surveys show that the stakeholders are satisfied with the NPSN [28], it is not flawless. On the night of December 30, 2020, a landslide occurred in Gjerdrum, Norway, destroying several apartments and houses and killing 10 people. The NPSN was frequently used in the emergency operation, but due to the high traffic in many different call groups, the base coverage was insufficient, and the users experienced blocked lines, and the actors could not access their call group.

The Norwegian government stated in 2014 that organizations beyond the core users (e.g. first responders) must have the opportunity to use the NPSN. However, this involves an application for access and a fee. According to the provider of the NPSN, the adoption and usage of the NPSN in these organizations is varying. The resulting problems occurring are exemplified in the management of the Viking Sky cruise ship accident outside the coast of Norway in 2019. The evaluation report documented that the lack of participation and access to the NPSN resulted in deficient communication during the operation, making it challenging to build a common situational understanding.

The communication in the NPSN is regulated by a set of union regulations that consists of expressions (e.g. "understood", "repeat", "received") to avoid misunderstandings, reduce the length of messages, and decrease disturbances [27].

To secure who gives what information to whom, there are several heuristic rules in the form of acronyms, a schema following a pre-defined template [21]. Some examples are MIMMS [29], METAFOR, and HENSPE [21] These structures are not a part of the NPSN regulations. No structure for information sharing includes the three-tiered $\mathrm{C} 2 \mathrm{~S}$ in a complex multi-organizational emergency operation.

\section{Common situational understanding}

All the stakeholders involved in a crisis operation work together to reach the multiteam overall goal of saving lives and reducing damage. For this to be successful, it is crucial to build and maintain a common situational understanding, and effective communication for coordinated decision making [25]. On the individual level, the stakeholders must have adequate situational awareness (SA) for their agencyspecific tasks. The concept of SA is defined by Endsley (1995) as "the perception of the elements in the environment within a volume of time and space, the comprehension of their meaning and a projection of their status in the near future." In a situation, there are several shared SA elements between the different stakeholders, which is defined in the literature as team SA [23]. Thus, it is not enough that one stakeholder knows an important SA element if it is important for several of the team members. At the operational C2S, the shared SA element can for example be smoke development. All first responders would then need to 
understand how this will affect their tasks and the other first responders' tasks for successful team performance. The smoke development can also be important for the tactical $\mathrm{C} 2 \mathrm{~S}$, and would thus be a shared SA element that needs to be communicated. However, at the strategic C2S, the smoke development might be less relevant and could distract the actors attention from their main tasks [30]. The idea of common situational understanding requires all the involved organizations to develop and maintain an adequate information position so they can develop a shared situational overview [9]. To achieve this, the involved organizations must be aware of each other's information needs [28] and share SA elements if it is a part of other organizations' SA requirements. However, even if stakeholders hold important SA elements, it is often challenging to know when, how, or with whom to share it [31].

All the involved organizations at the different C2S will mainly focus on their own information needs to make decisions. For example, the stakeholders at the operational C2S make decisions based on "knowledge by acquaintance" when they operate in dynamic and continually changing conditions. This requires realtime reactions [11] where the actor does not have the time to compare alternatives. This is called the Recognition-Primed Decision (RPD) model [32], where the actors react to their professional experiences and act in a way that they "know" will aid the specific condition. This is based on the identification of critical cues through professional assessment of the situation, evaluation, and implementation of an action. The tactic and strategic $\mathrm{C} 2 \mathrm{Ss}$ have an important role in supporting the activities at the operational C2S [19] and have the time to make decisions based on descriptions and checklists.

Since the stakeholders within the three-tiered C2S have different perspectives and information requirements for decision-making, the decisionmaking processes have different logic. Team sensemaking is defined as "the process by which a team manages and coordinates its efforts to explain the current situation and to anticipate future situations, typically under uncertain or ambiguous conditions" (Klein et al., 2010, p. 304). If team sensemaking succeeds, it seems to be an important implication for common situational understanding, as it stresses the differences in assumptions and helps stakeholders to understand each other's needs and constraints [4].

Muhren and Van de Walle (2010) identified three activities in the information and communication exchange process that were important for sensemaking among emergency stakeholders: (1) noticing, (2) interacting, and (3) enacting. Firstly, the actors must notice the important cues in the environment using both formal (e.g., inter-organizational structures) and informal channels (e.g., personal contacts). Secondly, the actors interact with others to update their situational understanding by staying informed, verifying and negotiating the information. Actors also interact with others to reflect on their decisions, often with a limited number of tools (such as the mobile phone) due to the time limits in emergency operations. Finally, actors must communicate to enable action [33]. This can be for example alerting the operative units to respond to a specific consequence of the emergency. Because stakeholders make sense of situations differently, it is important to acknowledge the need for negotiation in information sharing processes to achieve collective sensemaking.

\section{Methods}

The empirical basis for this study includes interviews of 33 Norwegian emergency management stakeholders from different levels of the command and control structures (Table 1). In addition, a survey from a multi-organizational exercise organized by the INSITU project [1] focusing on common situational understanding was used to supplement the interviews $(\mathrm{N}=29)$. The respondents of the survey used the NPSN for verbal communication in a tabletop exercise involving three large forest fires occurring simultaneously in different areas of Southern Norway. A survey consisting of 28 questions regarding the use of NPSN was sent out to all participants directly after the exercise. 29 participants had used the NPSN and answered the survey. Both the interviews and the survey were conducted by the author of this paper.

\subsection{Interviews}

Table 1 presents an overview of the interviewees. The interview guide was based on transcriptions of audio $\log$ s from a real forest fire in South Norway in May 2020. The author listened and transcribed all telephone and radio communication between involved stakeholders from the first hour of the operation from a fire $\mathrm{C} 3$. The communication was presented in the interview guide as an objective summary (due to confidentiality) of the information exchange between different actors. Some examples of communications from the beginning of the incident are 1. Location clarifications. 2. Emergency event - fire; what is burning - bushes. 3. Possible time since the origin. 4. Fire development. 5. Possibility to extinguish the fire. 6. Wind direction. For each information-sharing sequence (emergency dispatcher talking to the caller/lay bystander or other stakeholders), different questions were asked related to the information. For example, if their organization should be involved at that particular phase, they were asked about who they 
would contact, decision-making, the use of NPSN, and additional information needs.

The interview guide also had a semi-structured section with several open questions related to verbal communication in NPSN. There were also some agency-specific questions on the use of various call groups.

The interviews lasted 60-75 minutes. Fifteen interviews were conducted face to face, while 18 were online due to the escalating Covid-19 pandemic. Some of the interviews with the Incident Commanders (IC) from the first responders were group interviews (3 actors - Police IC, 2 actors - Ambulance IC, and 3 actors - Fire IC) because they usually negotiate and make decisions together at the command location on the emergency site.

Table 1: Overview of interviewees

\begin{tabular}{|l|l|c|}
\hline $\begin{array}{l}\text { Level of } \\
\text { command } \\
\text { structure }\end{array}$ & $\begin{array}{l}\text { Type of } \\
\text { organization }\end{array}$ & $\begin{array}{l}\text { Number of } \\
\text { participants }\end{array}$ \\
\hline Strategic & County Governor & 3 \\
\hline Strategic & Directorate & 1 \\
\hline Tactical & Police C3 & 6 \\
\hline Tactical & Ambulance C3 & 2 \\
\hline Tactical & Fire C3 & 2 \\
\hline Tactical & Civil Defence & 1 \\
\hline Tactical & Energy Company & 1 \\
\hline Tactical & Municipality & 1 \\
\hline Operative & Municipality & 2 \\
\hline Operative & Police IC & 4 \\
\hline Operative & Ambulance IC & 4 \\
\hline Operative & Fire IC & 4 \\
\hline Operative & Civil Defense IC & 1 \\
\hline Operative & Red Cross IC & 1 \\
\hline
\end{tabular}

All interviews were transcribed in full, translated from Norwegian into English, coded, and analyzed in NVivo. Firstly, the data were coded into the following categories: (1) what $\mathrm{C} 2 \mathrm{~S}$ he/she represented, (2) use/experiences with the NPSN, communication/information sharing structures, (4) needed information/lack of information, and (5) additional technologies. Secondly, within each communication sequence from the forest fire scenario, the coding included the following categories: (1) information needs, (2) alert of internal and external stakeholders, (3) decision making, (4) information requiring negotiation (see table 2 on how the information was structured), and (5) possible misunderstandings. Finally, the section with open questions was coded into the following categories: (1) Ideal message exchange, (2) ideal participants in the call group, and (3) reflection on different participant views. The different categories were eventually compared between the different $\mathrm{C} 2 \mathrm{~S}$ and analyzed using an inductive method. The answers from the survey were listed and coded into the following categories: (1) reflections on how to use common call groups, (2) actions/decisions based on the information flow in the common call group, and (3) benefits/disadvantages of being a part of the communication in the common call group.

Table 2: Information levels

\begin{tabular}{|l|l|}
\hline Syntactic & $\begin{array}{l}\text { Factual information that does not } \\
\text { have ambiguous meaning }\end{array}$ \\
\hline Semantic & $\begin{array}{l}\text { Information that may constitute } \\
\text { interpretive differences }\end{array}$ \\
\hline Pragmatic & $\begin{array}{l}\text { Information that may imply different } \\
\text { interests between the stakeholders } \\
\text { that must be resolved }\end{array}$ \\
\hline
\end{tabular}

\section{Results}

The results show that all three-tiered $\mathrm{C} 2 \mathrm{~S}$ depend on the same basic information to have the same understanding of the situation they are facing. First, all involved organizations need to know what kind of situation it is (for example, accident or terror) and must receive a confirmation or update after the first report/notice. Stakeholders on all levels mention that the information in the first notice is often inaccurate regarding both the incident and position. On the strategic $\mathrm{C} 2 \mathrm{~S}$, it is often a verbal notice from the tactic $\mathrm{C} 2 \mathrm{~S}$; on the tactic $\mathrm{C} 2 \mathrm{~S}$ it is often a call from a lay bystander, and on the operational $\mathrm{C} 2 \mathrm{~S}$ they are provided with a radio message/alert based on the first call received by the tactical C2S. Secondly, all threetiered $\mathrm{C} 2 \mathrm{~S}$ need to know what kind of resources the event seems to demand, whether the resources are on their way, and whether these resources are sufficient. Finally, all three-tiered $\mathrm{C} 2 \mathrm{~S}$ need an objective description of the situation, i.e. the stakeholders do not emphasize their own professional opinion. All involved stakeholders must have access to such a description as a substructure for the emergency operation. Several respondents pointed out that it is important not to describe the situation based on professional perspectives at the very beginning of the situation, because of the different views and experiences of stakeholders. As an example, a respondent from the ambulance service explained how a walking victim can be described as "appears undamaged" by other agencies; however, walking around can also be a symptom of severe head injury.

Having a heuristic rule for information sharing is frequently used internally in many agencies and some multi-agency operations involving first responders. 
This appears to be a constructive method for information sharing, and results from a HENSPE (ref section 2.1.1) course among first responders show that $93.4 \%$ of 1,192 participants thought that such a structure of information sharing could be beneficial in their everyday work (K. Styrkson, professional developer, The Norwegian Air Ambulance, personal communication, 21.04.2021). In the current study, the survey asked whether the respondents knew the HENSPE structure. $63 \%$ of the respondents had not heard of the structure, while $38 \%$ knew of the structure but did not use it. None of the participants used the structure.

The results of the interviews in this study indicate that there are some common information needs among the three-tiered $\mathrm{C} 2 \mathrm{~S}$, that are important for all involved stakeholders to establish a basic understanding of the situation (Table 3). This generates the acronym IERO.

Table 3: IERO acronym

\begin{tabular}{|l|l|}
\hline Incident & $\begin{array}{l}\text { Confirmation or update/ } \\
\text { rejection of the situation. }\end{array}$ \\
\hline Exact position & $\begin{array}{l}\text { Confirmation or } \\
\text { refuting/updating the position. } \\
\text { Clarify the GPS format. }\end{array}$ \\
\hline Resources & $\begin{array}{l}\text { Estimating the need for } \\
\text { resources. Multi-organizational } \\
\text { perspective. }\end{array}$ \\
\hline $\begin{array}{l}\text { Objective } \\
\text { description }\end{array}$ & $\begin{array}{l}\text { Description of the elements in } \\
\text { the environment, i.e., civilians, } \\
\text { victims, dangers, damage. }\end{array}$ \\
\hline
\end{tabular}

\subsection{Information needs at the different $\mathrm{C} 2$ structures}

The results indicate that there is a logical connection between the information needs at the different $\mathrm{C} 2 \mathrm{~S}$, with the tactical $\mathrm{C} 2 \mathrm{~S}$ functioning as a trading zone in the middle. Several of the information needs at the semantic and pragmatic level at the strategic and operational $\mathrm{C} 2 \mathrm{~S}$ are also present at the tactical C2S.

Based on the interviews, most of the information needs at the strategic $\mathrm{C} 2 \mathrm{~S}$ are at the syntactic level. This includes continuously updating the location, the number of people injured and dead, whether there are enough resources and the level of damage to critical infrastructure. These are elements that can be in an information system that functions as a COP. However, the level of severity, planning, and the operation progress need to be negotiated. One interviewee argued that it was important for them to think strategically and be supportive of the tactical and operational $\mathrm{C} 2 \mathrm{~S}$. Therefore, they must plan for possible future status, and based on their knowledge and guidelines, be one step ahead. However, this requires a common situational understanding of the current elements. Overall, the results from the interviews indicate that the strategic $\mathrm{C} 2 \mathrm{~S}$ requires information at the semantic and pragmatic level, which must be communicated directly from the operational and tactical $\mathrm{C} 2 \mathrm{~S}$. This view was echoed by the answers from the survey, where the respondents from the strategic $\mathrm{C} 2 \mathrm{~S}$ pointed out that they benefited from receiving information provided by the tactic and operational $\mathrm{C} 2 \mathrm{~S}$.

The information needs at the semantic and pragmatic level for the tactical $\mathrm{C} 2 \mathrm{~S}$ are as follows: level of severity, planning and operation progress, real and potential threats/dangers, evacuation, need for equipment, personnel, civilian overview, and time perspectives. The three first information needs are the same as for the strategic $\mathrm{C} 2 \mathrm{~S}$. Because the tasks for this $\mathrm{C} 2 \mathrm{~S}$ are based both on professional experience and policy, the information must become closer to the actual operation, as they have staff working on the emergency site. One respondent underpinned that they have an important role in the coordination work, and assessing the real and potential threats/dangers is crucial regarding personnel security. This is echoed by another respondent who stated that personnel security has a connection to equipment and evacuation, which involves knowing the quickest way and bottlenecks in and out of the emergency site for both civilians and personnel. All of this must be adapted to the time perspective of the emergency event and the operation. These aspects must be negotiated into a common understanding across the three $\mathrm{C} 2 \mathrm{~S}$.

At the operational $\mathrm{C} 2 \mathrm{~S}$, most of the information needs concern the different tasks that are needed and completed. There is a great deal of information at the syntactic level; however, the stakeholders must continually negotiate their perception of the elements to maintain a common situational understanding. The respondents reported that security, evacuation, number and condition of patients, and crossorganizational interpretation of how to handle the emergency event in general, is information that needs to be negotiated between the involved stakeholders at the $\mathrm{C} 2 \mathrm{~S}$. When the respondents were asked what kind of information they needed from the higher C2Ss, most indicated status on different requested resources and whether there are any dangerous elements near the emergency site were most important.

The results in this section indicate that there is a logical connection between the three $\mathrm{C} 2 \mathrm{~S}$ related to information at the semantic and pragmatic level of information sharing. However, the stakeholders must also be able to effectively share information for 
noticing, interacting, and enacting in order to build a common situational understanding. The next section, therefore, presents the results concerning how to structure the verbal information exchange using a common call group in the NPSN to facilitate interactive information sharing.

\subsection{Information sharing across the $\mathrm{C} 2 \mathrm{~S}$}

The results of the interviews revealed that the different organizations use various tools to share information, such as e-mail, textual logging, and NPSN. The first responders and supporting organizations are well-established users of the NPSN, but this seems not to be the case for the additional organizations. However, the results from the interviews and the survey indicate that it could be beneficial for all three $\mathrm{C} 2 \mathrm{~S}$ to have access to all the identified information needs using the NPSN. Respondents that do not use the NPSN every day, such as personnel from the municipality and county governor, said that it is difficult to organize the call groups and communication to support the more established tools such as e-mail and telephone. A respondent from the operational $\mathrm{C} 2 \mathrm{~S}$ who was not a first responder said that they had greatly benefited from common call groups. However, there was a lack of involvement from some stakeholders at the tactical and strategic $\mathrm{C} 2 \mathrm{~S}$.

When asked whether the verbal communication in a common call group supplemented syntactic level information, the majority $(90 \%)$ of the survey respondents were positive. Further, $72.4 \%$ answered that they received a high amount of relevant information that increased their situational awareness by having access to the information exchange in the call group. Additionally, a recurrent theme in the interviews was the benefit of using common call groups to build common situational understanding. Overall, the results indicate that access to a common call group is important; however, there is a need for pre-defined guidelines for different scenarios. For example, one respondent from the tactical C2S expressed that the communication usage in the NPSN is confusing and that many stakeholders have problems with the organization of the common call groups and knowing who should speak. Another respondent reported that the crisis staff must carry more radios to monitor several call groups because it is not possible to monitor several call groups simultaneously on one radio alone.

The respondents in the interviews and the survey were further asked to suggest how to structure the verbal communication for message exchange between the different $\mathrm{C} 2 \mathrm{~S}$. The respondents from the strategic $\mathrm{C} 2 \mathrm{~S}$ indicated that they would benefit from monitoring a common call group to gain a higher level of situational awareness. In some cases, the opportunity to negotiate information would help them to be a part of the operation in a more proactive way. A respondent from the strategic $\mathrm{C} 2 \mathrm{~S}$ said that by using a common call group, they could share information in real-time in a one-to-many modus, which could improve their sensemaking of the situation. However, communication paths must be pre-defined even if the organizations have access to the same common call group. One of the respondents said that the channel between the tactical $\mathrm{C} 2 \mathrm{~S}$ and the strategic $\mathrm{C} 2 \mathrm{~S}$ is important, but often missing. For example, the county governor could have a communication path against the involved directorate, the staff at the $\mathrm{C} 3$ in charge, and the municipality. Further, the different organizations at the tactical $\mathrm{C} 2 \mathrm{~S}$ must communicate with each other and the staff at the leading $\mathrm{C} 3$. At the operational $\mathrm{C} 2 \mathrm{~S}$, two divergent and often conflicting discourses emerged when discussing ways to structure verbal communication in a common call group. Particularly the actors from the first responders' agencies felt that their high workload meant that they did not have the time to participate in a common call group that involved organizations outside of the first responders. Other respondents (e.g., civil defense, energy company, red cross) believed it necessary to have such access. Hence, the results are somewhat conflicting between the different representatives from the operational C2S.

A majority of the respondents mentioned the importance of the communication discipline described in the NPSN regulations. This includes the expressions for avoiding misunderstandings between the stakeholders involved.

\section{Discussion}

In this paper, the research question asked was: What information elements must be exchanged at the semantic and pragmatic level between the involved organizations in extreme weather events, and how can this be facilitated by using a radio network? The inductive approach for analyzing the qualitative interviews with 33 Norwegian stakeholders from 9 different emergency management organizations indicates that the strategic, tactical, and operational C2Ss have several information needs that must be negotiated across the $\mathrm{C} 2 \mathrm{~S}$ to build a common situational understanding. In addition, some common initial information needs for building a basis for the involved stakeholders' SA were identified (the IERO structure). The sharing of these initial information needs can be structured as a heuristic rule. Using heuristic rules for information sharing is an efficient method for collecting and sharing information because 
communication processes can be complicated in stressful environments. For the information sharing to be effective, the sender must communicate in a way that the information is perceived and understood by the receiving party/ies [34]. Using an operative communication structure such as the IERO concept suggested in this study can be an effective solution. For example, implementing the elements in the IERO concept as part of the initiating actions of a common procedure can facilitate the development of an early common situational understanding.

During the emergency operation, semantic and pragmatic information needs must be shared across the C2S to build a common situational understanding. To achieve this, a more mutual and dynamic communication structure is required between the three-tiered C2S, as they are dependent on each other's knowledge, planning, and operation progress. The stakeholders have different professional backgrounds and perspectives on the situation, which makes the collaboration even more complex [7]. Another important issue that must be considered is mutual trust, as this is key to facilitate effective communication [34].The academic discussions on COP often refer to the warehouse philosophy [24], which mainly includes factual syntactic information [9]. The interviewees described several semantic and pragmatic information needs that should be communicated in real-time, including updates and negotiation of information. Negotiation is important for the process of team sensemaking both vertically and horizontally among the three-tiered C2S. Since team sensemaking concerns the involved stakeholders' understanding of the current and future status of a situation [32], it has a crucial impact on the content of the shared information. The semantic and pragmatic information levels require interaction and enacting, which is important for building team sensemaking among the involved stakeholders.

The semantic and pragmatic information needs at the strategic $\mathrm{C} 2 \mathrm{~S}$ support the strategic $\mathrm{C} 2 \mathrm{~S}$ 's role to think ahead and make decisions with a long-term impact on the situation [18]. For example, the level of severity has something to do with available resources, and this is important for the strategic $\mathrm{C} 2 \mathrm{~S}$ to understand. Of course, sharing factual information is important for common understanding. However, for this to be as effective as possible, the distribution of the information must facilitate interpretations and implications for decision-making based on factual information. The tactical C2 structure appears as the most complex level regarding information needs since they function as a trading zone between the strategic and operational C2Ss. The information needs at the strategic and operational C2Ss are also found among the information needs at the tactical C2S. The operational C2S decision-making is based on the RPD model, known as "knowledge by acquaintance" [35]. This makes the sensemaking process highly based on the activity of notice [33]. This might explain the expressed need for "cross-organizational interpretations" of different situations (section 5.1). The respondents at the operational $\mathrm{C} 2 \mathrm{~S}$ underpinned the importance of the collaboration at the incident command location on the emergency site. As the stakeholders at the operational C2S usually make rapid decisions based on the recognition of familiar cues [36], it is likely that the communication between actors is a continual discourse. Based on the results, Figure 2 demonstrates how a common call group can be used for information sharing. The black arrows represent communication paths within base coverage in the NPSN, while the blue arrows represent terminals in direct mode (e.g., for use without base station coverage). This will release network resources and enable the operation group to perform without interference from other users. For example, the communication blocks in the Gjerdrum landslide operation (see section 2.2.1) could have been avoided.

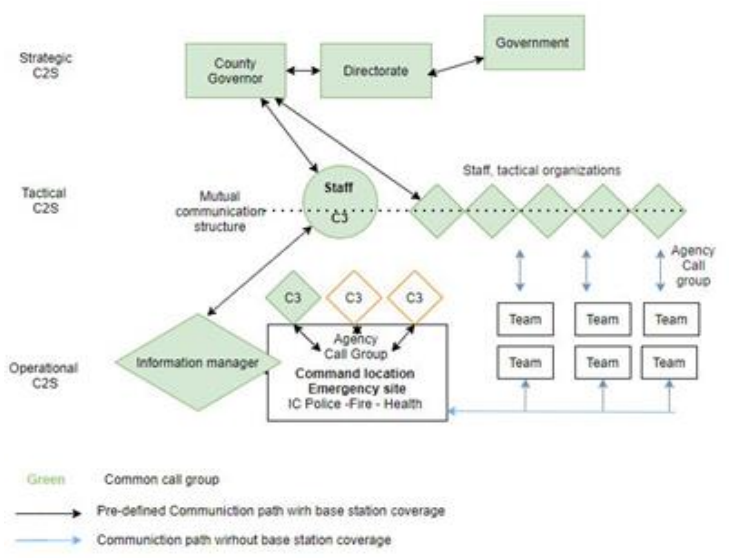

Figure 2: Using a common call group for information sharing

As Figure 2 demonstrates, the common call group is open for all the $\mathrm{C} 2 \mathrm{~S}$. As the majority of the stakeholders from the first responders in the operational $\mathrm{C} 2 \mathrm{~S}$ are quite determined that they cannot monitor any additional call group(s), several of them mentioned the opportunity for an information manager stationed at the command location. The information manager would support the IC by communicating with the other C2S [4]. The information manager must, in this case, be aware of the different information levels and function as a trading zone between the IC and the teams working in the front line. Further, the C3 in charge of the situation (in Norway this is often the 
Police) must be a part of the common call group. The strategic $\mathrm{C} 2 \mathrm{~S}$ have access to the common call group and thus have the opportunity to communicate with the different organizations at the lower level C2S. For these communication paths to be optimal predefined multi-organizational procedures must be well implemented at all $\mathrm{C} 2 \mathrm{~S}$, and the involved actors must receive practical training in advance. The training can be an important arena for building mutual trust as it is crucial for effective information sharing [34].

\section{Conclusions and further work}

The results of this study show that several information elements must be negotiated across the three-tiered $\mathrm{C} 2 \mathrm{~S}$ for collective sensemaking and common situational understanding. Today, the technical and organizational structures and processes between the C2Ss are not organized as one entity, and sharing verbal information in real-time is difficult to manage. The systems used between many stakeholders are technical solutions that share factual information at the syntactic level, such as text in logging systems or e-mail with or without various attachments. This is not sufficient for information sharing at the semantic and pragmatic levels, which is crucial for building common situational understanding. This paper suggests using a secure radio network to facilitate verbal communication. With pre-defined communication paths and knowledge of what information is important to negotiate, common call groups can be an important tool in multiorganizational emergency management involving the three-tiered $\mathrm{C} 2 \mathrm{~S}$. Further, the results add to the expanding field of the information sharing doctrine, focusing on the more implicit and complex concerns at the semantic and pragmatic level related to multiorganizational emergency management.

The practical implication of this study is the notion of the IERO structure. Using this as a heuristic/guideline can facilitate sharing common information that is needed at the beginning of an operation for building common situational understanding. Further, the emergency management organizations must consider the need for negotiation of different information elements, and facilitate the structure for communication that supplements the factual information that is provided by the COP. This can be done by developing multi-organizational guidelines for verbal status reports in a common call group (such as shown in figure 2) that support the need for negotiation on the pre-defined themes of information elements. Also, the focus on the tactical $\mathrm{C} 2 \mathrm{~S}$ as a trading zone and the role of information managers at the operational level seems to be important and necessary.
The generalizability of these results is subject to certain limitations. For instance, while the majority of other countries have only one emergency number, Norway has one dedicated emergency number for each of the different first responder agencies. The communication structures will therefore become somewhat different at the operational and tactical C2S. Despite this limitation, the study adds to our understanding of the need for information sharing at the semantic and pragmatic level, and how a public safety radio network and verbal communication can facilitate this. A greater focus on interpretations, implications, and collective sensemaking could produce interesting findings that can contribute to the discussion on COP and common situational understanding.

A question raised by this study is how the tactical $\mathrm{C} 2 \mathrm{~S}$ can facilitate a communicative trading zone between the strategic and the operational $\mathrm{C} 2 \mathrm{~S}$ without becoming the weakest link. Also, an extensive discussion on to what degree trust issues in information sharing between different organizations would affect the communication is recommended.

\section{References}

[1] Munkvold, B.E., Radianti, J., Rød, J.K., Opach, T., Snaprud, M., Pilemalm, S. \& Bunker, D. (2019). Sharing Incident and Threat Information for Common Situational Understanding. Proceedings of the 16th ISCRAM Conference, Spain.

[2] Harrald, J.R. (2006). Agility and discipline: Critical success factors for disaster response. The annals of the American Academy of political and Social Science, 604, 256-272.

[3] Bharosa, N., Lee, J. \& Janssen, M. (2010). Challenges and obstacles in sharing and coordinating information during multi-agency disaster response: Propositions from field exercises. Information Systems Frontiers, 12, 49-65.

[4] Wolbers, J. \& Boersma, K. (2013). The common operational picture as collective sensemaking. Journal of Contingencies and Crisis Management, 21, 186-199.

[5] Comfort, L. (2007). Crisis management in hindsight: Cognition, communication, coordination, and control. Public Administration Review, 67, 189-197.

[6] Karagiannis, G.M. \& Synolakis, C.E. (2016) Collaborative incident planning and the common operational picture. International Conference on Dynamics of Disasters. Springer, 91-112.

[7] Steen-Tveit, K., (2020), Identifying information requirements for improving the common operational picture in multi-agency operations. Proceedings of the $17^{\text {th }}$ ISCRAM conference, USA

[8] Looney, C.G. (2001). Exploring fusion architecture for a common operational picture. Information fusion, 2, 251260.

[9] Treurniet, W. \& Wolbers, J. (2021). Codifying a crisis: Progressing from information sharing to distributed 
decision-making. Journal of Contingencies and Crisis Management, 29, 23-35.

[10] Carlile, P.R. (2004). Transferring, translating, and transforming: An integrative framework for managing knowledge across boundaries. Organization science, $15,555-568$.

[11] Nja, O. \& Rake, E.L. (2009). A discussion of decision making applied in incident command. International Journal of Emergency Management, 6, 55-72.

[12] Carver, L. \& Turoff, M. (2007). Human-computer interaction: the human and computer as a team in emergency management information systems. Communications of the ACM, 50, 33-38.

[13] Waugh Jr, W.L. \& Streib, G. (2006). Collaboration and leadership for effective emergency management. Public administration review, 66, 131-140.

[14] Steen-Tveit, K., Radianti, J. \& Munkvold, B.E. (2020) Using Audio-Logs for Analyzing the Development of a Common Operational Picture in Multi-agency Emergency Response. Proceedings of the 53rd Hawaii International Conference on System Sciences, HI.

[15] Comfort, L.K., Ko, K. \& Zagorecki, A. (2004b). Coordination in rapidly evolving disaster response systems: The role of information. American Behavioral Scientist, 48, 295-313.

[16] Boin, A. \& 'T Hart, P. (2010). Organising for effective emergency management: Lessons from research 1. Australian Journal of Public Administration, 69, 357371.

[17] Mcentire, D.A. (2007). Disciplines, disasters, and emergency management: The convergence and divergence of concepts, issues and trends from the research literature, Charles $\mathrm{C}$ Thomas Publisher

[18] Waring, S., Alison, L., Shortland, N. \& Humann, M. (2020a). The role of information sharing on decision delay during multiteam disaster response. Cognition, Technology \& Work, 22, 263-279.

[19] Owen, C., Brooks, B., Bearman, C. \& Curnin, S. (2016). Values and complexities in assessing strategiclevel emergency management effectiveness. Journal of Contingencies and Crisis Management, 24, 181-190.

[20] Waring, S., Alison, L., Carter, G., Barrett-Pink, C., Humann, M., Swan, L. \& Zilinsky, T. (2018). Information sharing in interteam responses to disaster. Journal of occupational and organizational psychology, 91, 591-619.

[21] Bjelland, B. \& Nakstad., R.E. (2018). Beredskap, kriseledelse og praktisk skadestedsarbeid, Oslo, Gyldendal Akademisk.

[22]. Comfort, L. K., Dunn, M., Johnson, D., Skertich, R. \& Zagorecki, A. (2004a). Coordination in complex systems: increasing efficiency in disaster mitigation and response. International Journal of Emergency Management, 2, 62-80.

[23] Endsley (1995). Toward a theory of situation awareness in dynamic systems. Human Factors, 37, 32-64.

[24] Leedom, D.K. (2003) Functional analysis of the next generation common operating picture. Proceedings of the 8th annual International Command and Control Research and Technology Symposium.
[25] Hwang, G.H. \& Yoon, W.C. (2020). A new approach to requirement development for a common operational picture to support distributed situation awareness. Safety Science, 125, 104569.

[26] Nødnett.No. Development of Nфdnett retrieved at: http://www.nodnett.no/Nodnett/utbygging-av-nodnett/

[27] DSB (2018). Felles sambandsregelement for Nødnett. Retrieved from: https://www.nodnett.no/globalassets/fellessambandsreglement-for-nodnett.pdf

[28] Norri-Sederholm, T., Joensuu, M. \& Huhtinen, A.-M. (2017). Ensuring Information Flow and the Situation Picture in Public Safety Organisations' Situation Centres. European Conference on Cyber Warfare and Security, Proceedings of the Academic Conferences International Limited, 267-273.

[29] Cypko, M.A. (2020). Development of a Clinical Decision Support System. Development of Clinical Decision Support Systems using Bayesian Networks. Springer.

[30] Alexander, D.E. (2014). Social media in disaster risk reduction and crisis management. Science and engineering ethics, 20, 717-733.

[31] Kontogiannis, T., Leva, M. \& Balfe, N. (2017). Total safety management: principles, processes and methods. Safety science, 100, 128-142.

[32] Klein, G. A., Orasanu, J., Calderwood, R. \& Zsambok, C. E. (1993). Decision making in action: Models and methods, Ablex Norwood, NJ.

[33] Muhren, W.J. \& Van De Walle, B. (2010). Sensemaking and information management in emergency response and Technology. Bulletin of the American Society for Information Science, 36, 30-33.

[34] Etherington, N., Wu, M., Cheng-Boivin, O., Larrigan, S. \& Boet, S. (2019). Interprofessional communication in the operating room: a narrative review to advance research and practice. Canadian Journal of Anesthesia/Journal canadien d'anesthésie, 66, 12511260.

[35] Klein, G., Wiggins, S. \& Dominguez, C.O. (2010). Team sensemaking. Theoretical Issues in Ergonomics Science, 11, 304-320.

[36] Waring, S., Moran, J.L. \& Page, R. (2020b). Decisionmaking in multiagency multiteam systems operating in extreme environments. Journal of Occupational and Organizational Psychology, e12309.

[37] Rimstad, R. \& Sollid, S.J. (2015). A retrospective observational study of medical incident command and decision-making in the 2011 Oslo bombing. International journal of emergency medicine, 8, 1-10. 